Наносистели, нанолатеріали, нанотехнології Nanosistemi, Nanomateriali, Nanotehnologii 2020 , т. 18, № 2, сc. 241-252 (c) 2020 ІМФ (Інститут металофізики ім. Г. В. Курдюмова НАН України) Надруковано в Україні. Фотокопіювання дозволено тільки відповідно до ліцензі

PACS numbers: 71.20.Nr, 71.35.Ji, 71.35.Pq, 73.20.Mf, 73.21.Fg, 78.55.-m

\title{
Hybridization of Direct and Indirect Exciton States in Double
} Quantum Wells CdMgTe/Cd ${ }_{0.95} \mathrm{Mn}_{0.05} \mathrm{Te} / \mathrm{CdMgTe} / \mathrm{CdTe} / \mathrm{CdMgTe}$ \author{
and G. Karczewski ${ }^{3}$ \\ ${ }^{1}$ Institute of Physics, N.A.S. of Ukraine, \\ 46, Nauky Ave., \\ UA-04028 Kyiv, Ukraine \\ ${ }^{2}$ Institute of Nuclear Research, N.A.S. of Ukraine, \\ 47, Nauky Ave., \\ UA-04028 Kyiv, Ukraine \\ ${ }^{3}$ Institute of Physics, Polish Academy of Sciences, \\ $32 / 46$, Al. Lotnikow, \\ 02668 Warsaw, Poland
}

O. V. Terletsky ${ }^{1}$, S. M. Ryabchenko ${ }^{1}$, V. I. Sugakov ${ }^{2}$, G. V. Vertsimakha ${ }^{2}$,

The photoluminescence from CdMgTe/ $\mathrm{Cd}_{0.95} \mathrm{Mn0}_{.05} \mathrm{Te} / \mathrm{CdMgTe} / \mathrm{CdTe} / \mathrm{CdMgTe}$ double quantum wells with $\mathrm{Cd}_{0.95} \mathrm{Mn}_{0.05}$ Te well width of $46 \mathrm{ml}(15 \mathrm{~nm})$ and with several various CdTe wells' widths is experimentally studied at the temperature of about $2 \mathrm{~K}$ in magnetic field up to $4.5 \mathrm{~T}$ in the region of intersection of magnetic-field dependences of exciton lines for spatially direct and spatially indirect exciton states. The discussed exciton lines correspond to the direct exciton localized in the $\mathrm{Cd}_{0.95} \mathrm{Mn}_{0.05} \mathrm{Te}$ quantum well and the indirect exciton with both the electron localized in the CdTe well and the heavy hole localized in the $\mathrm{Cd}_{0.95} \mathrm{Mn}_{0.05} \mathrm{Te}$ one. The energies of the exciton states are calculated within the variation approach. Differences between the magnetic-field dependences of the exciton lines in the region of the lines' intersection and far from this region are revealed in experiments and are found in fulfilled calculations. As concluded, the region of these exciton lines' crossing corresponds to the crossing of the energy positions of lowest spatially-quantized state of the conductivity electron in CdTe well with magnetic-field dependence of similar electron state in $\mathrm{Cd}_{0.95} \mathrm{Mn}_{0.05} \mathrm{Te}$ well.

Експериментально вивчалася фотолюмінесценція від подвійних квантових ям $\mathrm{CdMgTe} / \mathrm{Cd}_{0,95} \mathrm{Mn}_{0,05} \mathrm{Te} / \mathrm{CdMgTe} / \mathrm{CdTe} / \mathrm{CdMgTe} з$ шириною квантової ями $\mathrm{Cd}_{0,95} \mathrm{Mn}_{0,05}$ Те у 46 мл (15 нм) і з кількома різними ширинами ям CdTe за температури у $2 \mathrm{~K}$ та у магнетному полі до $4,5 \mathrm{~T}$ в околі перетину магнетнопольових залежностей екситонних ліній для просторово прямого та просторово непрямого екситонів. Спостережені екситонні 
лінії відповідають прямому екситону, локалізованому у квантовій ямі $\mathrm{Cd}_{0,95} \mathrm{Mn}_{0,05} \mathrm{Te}$, та непрямому екситону з електроном, локалізованим у ямі $\mathrm{CdTe}$, і важкою діркою, локалізованою у ямі $\mathrm{Cd}_{0,95} \mathrm{Mn}_{0,05}$ Те. Енергії екситонних станів було розраховано у варіяційному підході. Виявлені експериментально та чисельними розрахунками відмінності у магнетнопольових залежностях екситонних ліній в околі та віддалеки від їхнього перетинання відповідають перетину енергій найнижчого просторово квантованого стану електрона провідности у ямі CdTe та магнетнопольової залежности найнижчого просторово квантованого електронного рівня у ямі $\mathrm{Cd}_{0,95} \mathrm{Mn}_{0,05} \mathrm{Te}$.

Экспериментально изучается фотолюминесценция от двойных квантовых ям $\mathrm{CdMgTe} / \mathrm{Cd}_{0,95} \mathrm{Mn}_{0,05} \mathrm{Te} / \mathrm{CdMgTe} / \mathrm{CdTe} / \mathrm{CdMgTe}$ с шириной ямы $\mathrm{Cd}_{0,95} \mathrm{Mn}_{0,05} \mathrm{Te}$ в 46 мл (15 нм) и с несколькими различными ширинами ям CdTe при температуре около $2 \mathrm{~K}$ в магнитном поле до 4,5 T в области пересечения магнитнополевых зависимостей экситонных линий для пространственно прямых и пространственно косвенных экситонных состояний. Обсуждаемые экситонные линии соответствуют прямому экситону, локализованному в квантовой яме $\mathrm{Cd}_{0,95} \mathrm{Mn}_{0,05} \mathrm{Te}$, и косвенному экситону с электроном, локализованным в яме CdTe, и тяжёлой дырке, локализованной в яме $\mathrm{Cd}_{0,95} \mathrm{Mn}_{0,05} \mathrm{Te}$. Энергии экситонных состояний рассчитываются в рамках вариационного подхода. Различия между магнитнополевыми зависимостями экситонных линий в области пересечения линий и вдали от этой области обнаруживаются в экспериментах и обнаруживаются в выполненных расчётах. Область пересечения этих экситонных линий соответствует пересечению энергетических позиций самого низкого пространственно-квантованного состояния электрона проводимости в яме CdTe и магнитнополевой зависимости аналогичного электронного состояния в яме $\mathrm{Cd}_{0,95} \mathrm{Mn}_{0,05}$.

Key words: double quantum well, electron tunnelling, direct and indirect excitons, giant spin splitting of the exciton branches.

Ключові слова: подвійні квантові ями, електронне тунелювання, прямі та непрямі екситони, гігантське спінове розщеплення екситонних станів.

Ключевые слова: двойные квантовые ямы, электронное туннелирование, прямые и непрямые экситоны, гигантское спиновое расщепление экситонных состояний.

(Received 3 December, 2019)

\section{INTRODUCTION}

As it was theoretically substantiated and experimentally confirmed about twenty years ago, in double quantum wells $(2 Q W \mathrm{~s})$, elementary excitations of so-called indirect excitons (IXs) can be created. The maxima of the wave functions of electrons and holes forming such 
excitons are localized in different adjacent quantum wells. Most often, experimental studies of IXs are carried out for symmetric double wells in electric fields applied normally to the plane of the wells. Such fields violate symmetry of wells in $2 Q W$. The photoluminescence (PL) is usually observed from one out of two possible IX transitions upon optical excitation with quanta energy close to the Pl energy of the direct excitons (DXs) in this structure. The energy of the investigated indirect exciton in this case becomes the lowest one among the excited states in this structure, whereas the energy of the second possible IX state is higher than for DX, so the PL of this IX is not observed. The authors of [1-8] showed that the states of indirect excitons observed in this way show a tendency to Bose-Einstein condensation, which becomes possible due to the accumulation of indirect excitons, in which the probability of radiative recombination is very small compared to the probability for direct excitons.

Another way for experimental observation of indirect excitons in double quantum wells is to study double quantum wells, one of which is either created from a diluted magnetic semiconductor (DMS) or its external in respect to $2 Q W \mathrm{~s}$ barrier is created from DMS (see, for example, [9-14]). In this case, the quantum wells are asymmetric. Here, tuning the energy positions of the carriers' states in the DMS $Q W$ (or in $Q W$ bordering with DMS barrier) is possible due to the giant spin splitting of the exciton states in the external magnetic field [15, 16]. Spin splitting leads to the fact that the energies and conditions of observation of excitons with different spin polarization of the charge carriers forming the exciton will be different. In particular, in the luminescence, only spinpolarized excitons with the lowest energy between spin-splitted states will be observed. A theoretical study IX in such systems in the variational approach was carried out in $[17,18]$.

It is possible to select parameters of the quantum wells in the asymmetrical double-well structure so that at least the lowest spatially quantized zones of the electrons in two neighbour wells will have matching energies. In this case, tunnelling of electrons between these zones will become resonant.

The main subject of this work is the observation of excitons in a double well structure where tunnelling of electrons between the coupled wells is close to resonant. In principle, the same can be realized for heave holes too, but the probability of the tunnelling for heave holes is much less than for electrons due to the larger effective mass of the holes.

In addition, for holes in the DMS well, dependence of the energy of the hole states on the magnetic field is stronger than for electrons that complicates observation of possible effects. Therefore, we will not consider this case in this paper. 


\section{STRUCTURES UNDER STUDY AND EXPERIMENTAL RESULTS}

In the paper, we investigate magnetic field dependences of the luminescence of direct and indirect excitons formed by charge carriers of the lowest spatially quantized states of electrons and heavy holes of two coupled quantum wells. One of these $Q W \mathrm{~s}$ is made of magnetically mixed (diluted magnetic) $\mathrm{Cd}_{1-x} \mathrm{Mn}_{x} \mathrm{Te}$ semiconductor with $x=0.05$, and the other is formed with the CdTe. In such structures, it is possible to observe IX transitions of two types depending on in which of $Q W \mathrm{~s}$, the electron and/or hole are located with dominant probability. Herein, we will name such states as $1 e_{\mathrm{CdMnTe}}{ }^{-}$ $1 h h_{\mathrm{CdTe}}$ state and $1 e_{\mathrm{CdTe}}-1 h h_{\mathrm{CdMnTe}}$ state. The indices CdMnTe and CdTe indicate the material of the well, in which the electron $(e)$ or the heavy hole $(h h)$ is predominantly located. The oscillator strengths for these indirect transitions are caused by the mixing of
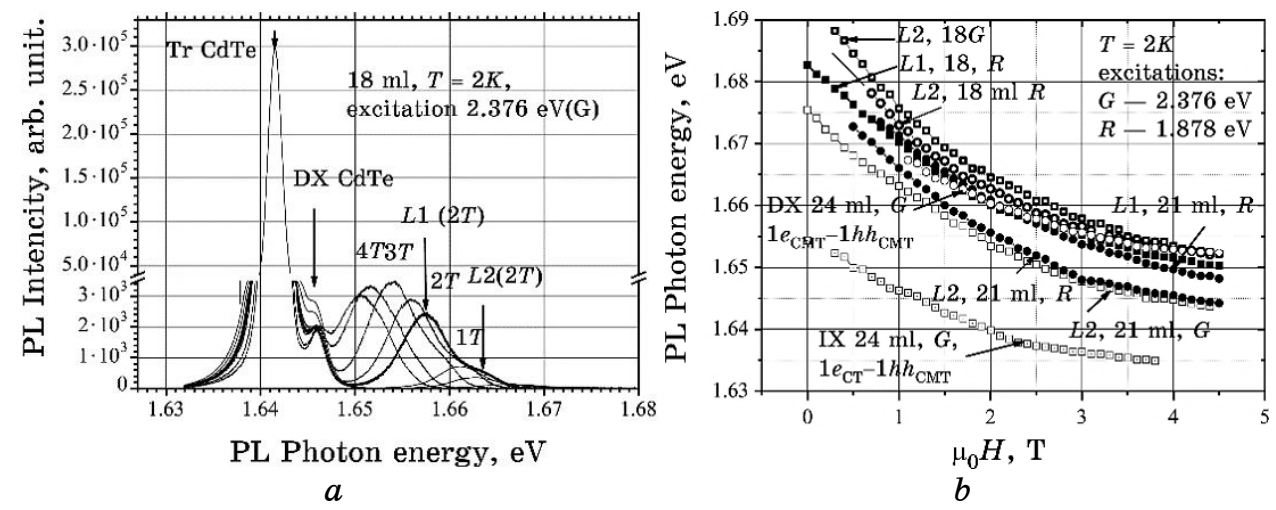

Fig. 1. a) Distribution of intensity of PL in the structure with $18 \mathrm{ml}$-width CdTe well for different values of the magnetic field up to $4.0 \mathrm{~T}$ in case of the $G$-excitation $(2.376 \mathrm{eV})$. Positions of the $L 1$ and $L 2$ lines are arrowed in the field of $B=2 \mathrm{~T}$. The magnetic field values to which correspond the shown lines are pointed only near of the $L 2$ line maxima. One can see that the charged exciton (trion) line from the CdTe $Q W$ prevails in the spectrum and exceeds by almost two orders of magnitude the DX line intensity for this $Q W ; b$ ) Dependence of the exciton lines' maxima on the magnetic field for the structures with $Q W$ CdTe wells widths equal to $L_{\mathrm{CdTe}}=18,21$ and $24 \mathrm{ml}$ for $R$ and/or the $G$ excitations. The lines' positions for the direct excitons and trions from the $\operatorname{CdTe} Q W$, which do not depend on the magnetic field, are not shown. Positions of the PL maxima for different lines in each structure and for the structures with different $L_{\mathrm{CdTe}}$ widths are shown by the different symbols. Assignment of each line of the shown dependences to a concrete studied structure or the PL line connected with this structure is indicated by the inscriptions in the Fig. 1, $b$. 
the state of direct excitons to the corresponding indirect excitons. This mixing is caused in main part by the matrix elements of electron tunnelling between the wells. At the same time, a contribution of heavy holes' tunnelling can be neglected because this process is much less probable. So, each of mention indirect excitons obtain in main part its oscillator strengths due to some mixing with that direct exciton which has heavy hole in the same well that and this indirect one.

Studied $\mathrm{Cd}_{0.72} \mathrm{Mg}_{0.28} \mathrm{Te} / \mathrm{Cd}_{0.95} \mathrm{Mn}_{0.05} \mathrm{Te} / \mathrm{Cd}_{0.72} \mathrm{Mg}_{0.28} \mathrm{Te} / \mathrm{CdTe} / \mathrm{Cd}_{0.72} \mathrm{Mg}_{0.28} \mathrm{Te}$ structures were grown by the MBE method (0416 series). The width of the $\mathrm{Cd}_{0.95} \mathrm{Mn}_{0.05} \mathrm{Te} Q W, L_{\mathrm{CdMnTe}}$, was equal to $46 \mathrm{ml}$ for all the samples, whereas the widths of the CdTe wells were different, namely, equal to $L_{\mathrm{CdTe}}=27,24,21$ and $18 \mathrm{ml}$. The barriers width between the DMS and CdTe $Q W \mathrm{~s}$ were equal to $L_{b}=6 \mathrm{ml}=1.944 \mathrm{~nm}$ for all the samples. Hereinafter, $1 \mathrm{ml}=0.324 \mathrm{~nm}$ is the thickness of the monatomic layer in [100]-oriented structures based on CdTe. The PL measurements were predominantly carried out with the above the barrier excitation with the $E_{e x}=2.376 \mathrm{eV}$ energy (green, $G$ ) or sub-barrier one with the $E_{e x}=1.878 \mathrm{eV}$ energy (red, $R$ ) with non-polarized light. A typical spectral distribution of the intensity of the exciton PL lines for the $\sigma^{+}$-polarization and their energy position for $2 Q W$ with $L_{\mathrm{CdTe}}=18 \mathrm{ml}$ under the $G$-excitation are shown in Fig. 1, $a$.

One can see from Fig. 1, $b$ that the magnetic field induced energy shifts of the Line1, Line2 exciton lines are almost the same, and their field dependences are almost parallel over the all magnetic field interval up to $4.5 T$. The energy distance between them approximately equal to $\Delta E \approx 6 \pm 1 \mathrm{meV}$, and the shift of the lines in the magnetic field reaches the value of $33 \mathrm{meV}$ in the field of $4.5 \mathrm{~T}$. Such lines' behaviours do not agree with representation that one of lines connected with DX and other with IX in our structure. The magnetic field induced energy shifts for PL line from the IX of considered type should be on $20 \%$ smaller than for PL line from DX in DMS $Q W$. In Figure 1, $b$, we can see that for the samples with CdTe $Q W$ width 18 and $21 \mathrm{ml}$ there are a group of lines that coincide (up to measurement error values) with the line of the direct exciton for the sample with the CdTe $Q W$ width of $24 \mathrm{ml}$. The PL lines of the direct exciton in the DMS well and indirect $1 e_{\mathrm{CdTe}}-1 h h_{\mathrm{CdMnTe}}$ exciton are in this sample energetically well-spaced. The lines of this group for the samples with the 18 and $21 \mathrm{ml}$ CdTe $Q W$ widths deviate somewhat in energy from the dependence for a sample with the $24 \mathrm{ml}$ CdTe $Q W$ width in small and large magnetic fields. The values of these deviations small exit beyond the experimental errors, so, we will not build any conclusions about their nature. We only note that the magnetic field dependence of the DX's energy in the CdMnTe $Q W$ should not 
depend on the width of the adjacent CdTe well. So, the lines of this group, even with their small mismatch, are genetically related to the direct exciton in the CdMnTe $Q W$.

At the same time, we have one more line in Fig. 1, $b$ for each of the samples with the CdTe $Q W$ widths equal to 18 and $21 \mathrm{ml}$, which in intensity is comparable with lines that are part of the abovementioned group of the PL lines (Line1) associated with DXs in the DMS wells of these samples. In the sample with $L_{\mathrm{CdTe}}=18 \mathrm{ml}$, this additional component of the doublet of lines PL, $L 2$, is strongly dependent on the magnetic field and is shifted with respect to the mentioned group of the lines connected with DX in DMS $Q W$ to the high-energy spectral region. At the same time, this, second line of the PL doublet, L2, which depends on the magnetic field for the sample with the $21 \mathrm{ml}$ width $\mathrm{CdTe} Q W$, is already shifted to the low-energy spectral region with respect to the lines connected with DX in the DMS $Q W$. Therefore, in the range of the CdTe $Q W$ widths from 18 to $21 \mathrm{ml}$, there is the intersection of the magnetic field dependences of the direct exciton in the DMS $Q W$ and the indirect one $1 e_{\mathrm{CdTe}}-1 h h_{\mathrm{CdMnTe}}$ type, that is, they are passing through the resonance.

In Figure 2, $a, b$, the maps of the logarithm of the intensities of the PL spectra for two structures with different CdTe widths of the quantum wells on each sides of this 'resonance' are presented. One can see from these maps dependences of the intensities of the lines, which energies depend on the magnetic field magnitude. It is seen also that Line 1 in both cases, for 18 and $21 \mathrm{ml}$ CdTe $Q W$ width, have in main part close one to another magnetic field dependences in the same time as $L 2$ has higher energy than $L 1$ in case of $18 \mathrm{ml}$
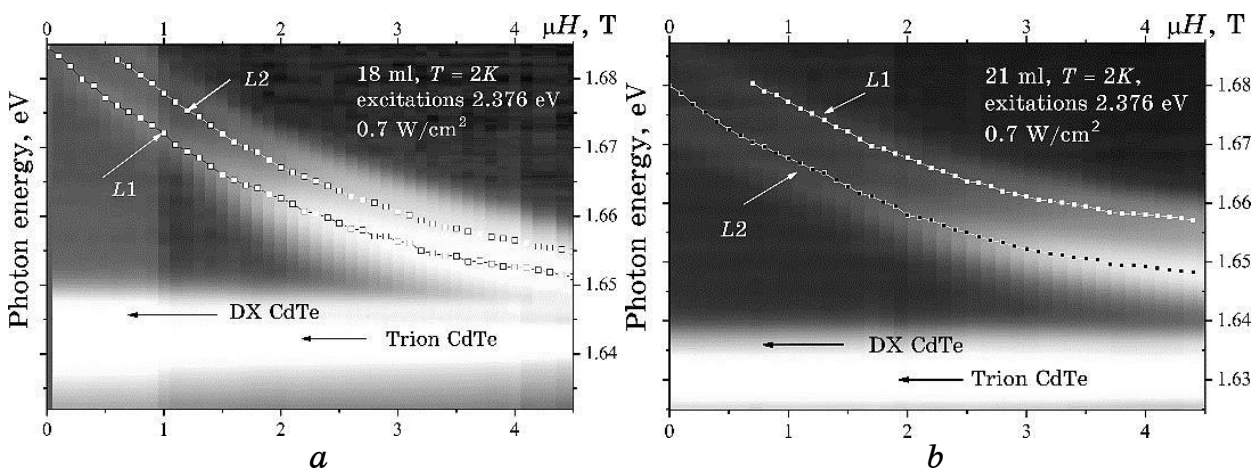

Fig. 2. Maps of the PL intensity (in a logarithmic scale) of the spectra of the structures with the $18 \mathrm{ml}(a)$ and $21 \mathrm{ml}(b)$ CdTe widths in case of the PL excitation by $2.376 \mathrm{eV}$ quanta. A duplicate structure of lines of $L 1 \mathrm{\text {та }}$ $L 2$ is the article of this article and comes into question in text. 
CdTe $Q W$ width and lower in case $21 \mathrm{ml}$. Therefore, the Line1 in bigger part is more substantially connected with DX in DMS $Q W$ and Line2 with IX. In addition, dependences of PL energy on the magnetic field for these excitons are crossed one another in 18-21 $\mathrm{ml}$ interval of CdTe $Q W$ width.

\section{DISCUSSION OF THE EXPERIMENT AND SOME ESTIMATES CONCERNING EXCITONS IN $2 Q W$ STRUCTURES}

The exciton energy in a particular quantum well consists of the difference in the energies of the spatially quantized states in which the electron and the hole are located minus the Coulomb binding energy between of the electron and the hole. The hole is localized in the same spatially quantized state for both the direct and indirect excitons that we consider. It concern to both for the parameters region of coinciding of the electron energies in different wells with taking into account the hole's electrical fields for these excitons and for regions where energies of these electron are noticeable different. As it is known from quantum mechanics (for example, [19]), when take place the energy resonance of two eigenstates in the same basis, their wave functions form a superposition such that in the region of 'exact resonance' the superposition turns into their symmetric and antisymmetric combination. Contributions of both unperturbed states to this combination should be the same. If we neglect the possible difference in the Coulomb binding energy of the hole in the DMS well with the symmetric and antisymmetric electronic state in the wells, then the binding energy of the symmetric and antisymmetric hybrid (semi-direct and semi-indirect) excitons will be the same. In this case, the resonance of the excitons is caused by the energy resonance of the spatially quantized states of the electron in the wells with taking into account of action on these states of electrical field of heavy hole in DMS $Q W$. In this case, the splitting (antiresonance) of two states of the excitons in $2 Q W \mathrm{~s}$ structure that include the symmetric and antisymmetric electron states in $2 Q W$ s structure will be close or will coincide with the value of the matrix element of the resonant electron tunnelling between quantum wells. This matrix element may be not so small taking into account the small width of the barrier between the wells ( 6 $\mathrm{ml}=1.944 \mathrm{~nm}$ ) and the small effective electron mass (about $0.1 \mathrm{~m}_{0}$, where $\mathrm{m}_{0}$ is the free electron mass).

To estimate the magnetic field dependence of the exciton lines close to the doublet, first, the energy difference of the $1 e$ and $1 \mathrm{hh}$ states was calculated for the DMS $\mathrm{Cd}_{0.95} \mathrm{Mn}_{0.5} \mathrm{Te} Q W$ and CdTe $Q W$ at different widths of the CdTe wells.

The calculated difference of energies of spatially quantized levels 

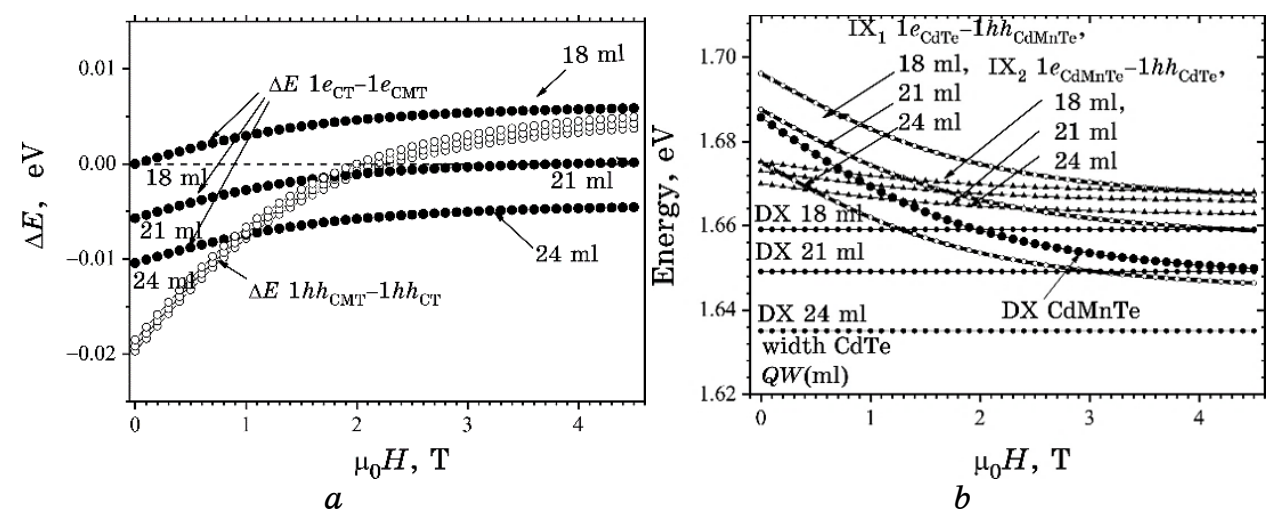

Fig. 3. a) Calculated energy differences for the $1 e$ states and for the $1 \mathrm{hh}$ ones in the $Q W \mathrm{~s} \mathrm{Cd}_{0.95} \mathrm{Mn}_{0.05} \mathrm{Te}$ and CdTe for different widths of the CdTe wells, namely, 18, 21 and $24 \mathrm{ml} ; b$ ) The magnetic field dependences of the energies of the direct excitons for $\mathrm{CdTe}$ and $\mathrm{CdMnTe} Q W \mathrm{~s}$ and indirect excitons of the $1 e_{\mathrm{CdTe}}-1 h h_{\mathrm{CdMnTe}}$ and $1 e_{\mathrm{CdMnTe}}-1 h h_{\mathrm{CdTe}}$ types. Calculations carried out without taking into account a possible change of the bounding energies of the excitons in the region of the energy resonances of different excitons.

$1 e$ and $1 \mathrm{hh}$ in different wells of $2 Q W \mathrm{~s}$ system that shown in Fig. 3, $a$ indicate that in certain fields for the samples with $18 \mathrm{ml}$ and in other fields for $21 \mathrm{ml}$, the $1 e$ levels for the CdTe and CdMnTe wells coincide. Under these conditions, the tunnelling should take place as resonant with repulsion of the energies of the $1 e$ states located in such case simultaneously in the both wells and mixing of the initial $1 e$ wave functions of different $Q W \mathrm{~s}$. Under such conditions, the notion of direct and/or indirect excitons becomes meaningless. The electron will be delocalized with noticeable probabilities to be found in both quantum wells and its two states should be classified as symmetric and antisymmetric ones with respect to the electron in these wells. At the same time, the heavy hole of these excitons will be localized mainly in one of the wells, because it tunnels through the $6 \mathrm{ml}$ barrier much worse than the light electron.

The calculations of the energies of the $1 e$ states for the $46 \mathrm{ml}$ width $\mathrm{Cd}_{1-x} \mathrm{Mn}_{x} \mathrm{Te} Q W$ and the CdTe $Q W$ s with 13 to 24 ml widths, (see Fig. 4) indicate that upon the resonance of the unperturbed $1 e$ states in the CdMnTe and CdTe wells their splitting due the tunnelling takes place. This splitting at the anticrossing point reaches the value of $\Delta E_{\text {cros }} \cong 4.75 \mathrm{meV}$. The calculation shown in Fig. 4 shows that the resonance tunnelling affect is expanded over the widths' region of CdTe $Q W \pm 1 \mathrm{ml}$ from the conditions of exact resonance. So, under the condition of the resonance of the electronic states considered with 


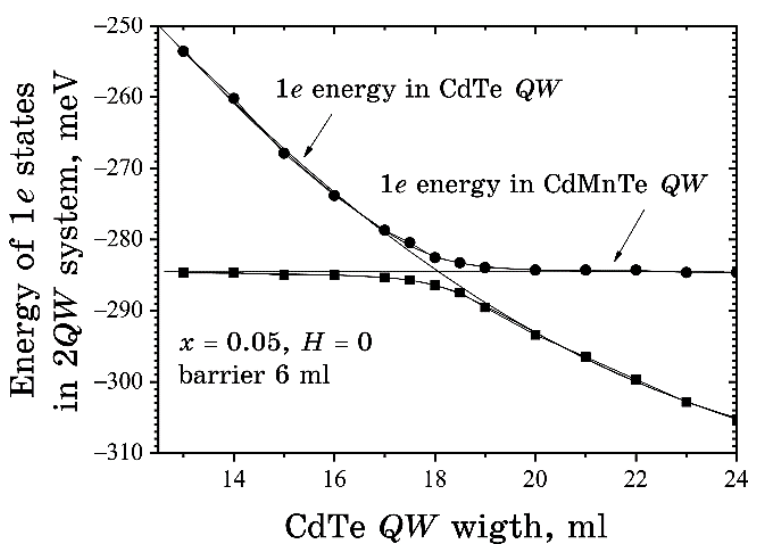

Fig. 4. Calculated $1 e$ energies in the considered $2 Q W$ system. The energy is counted from the barrier position. The tunnel splitting in resonance is equal to $d=4.775 \pm 0.05 \mathrm{meV}$. The tunnel matrix element between the $1 e$ states in the $Q W \mathrm{~S}$ is equal to $d / 2 \approx 2.4 \mathrm{meV}$. The thin lines show the unperturbed dependence of the $1 e$ states' energies.

taking into account the influence of electrical field of the hole, the splitting of the hybrid excitons due to the 'anticrossing' can reach a value that goes beyond the limits of measurement errors. In this case, for both the lines of the direct and indirect excitons, their magnetic field dependences should deviate from the unperturbed values in the vicinity of the intersection, although their dependences that unperturbed by resonant tunnelling intersect. So, we can expect deviations of the dependences of the energies from magnetic field for the direct excitons in the DMS $Q W$ within $\approx 3 \mathrm{meV}$ for the samples with CdTe $Q W$ widths of 18 and $21 \mathrm{ml}$ from the case of a sample with a CdTe well width of $24 \mathrm{ml}$, where the effect of the intersection of the field dependences of DX and considered IX is surely absent. Such deviations are present in the experiment (see Fig. 1, b).

The question arises, why is the resonance not localized in certain magnetic fields, and the parallelism of the magnetic field dependences of both PL lines of the doublet (Fig. 2) is observed over almost all the interval of the magnetic fields used in the experiment? To answer this question, several circumstances should be taken into account. First, it is necessary to take into account dependence of the exciton binding energy on the difference of the unperturbed values of their energies, or in other words, on the hybridization of the $1 e$ electronic states in the wells. This difference unperturbed values energies realized in our experiment through dependence these values on the magnetic field.

This dependence will 'deform' the magnetic field dependence of the observed difference in the exciton PL energies. In addition, the 
structures under study had a certain inhomogeneity of parameters, which was manifested in small changes the energies of the PL line maxima as the PL excitation point moved along the sample plane. That could contribute to an inhomogeneous distribution over the sample's plane of the magnetic field corresponding to the 'exact resonance' field of the unperturbed energies of the hybridized excitons. This effect will also 'stretch' the resonance conditions over the fields. Especially, if we take into account that the entire dependence of the energy of the electronic state in $\mathrm{Cd}_{1-x} \mathrm{Mn}_{x} \mathrm{Te}$ with $x=0.05$ from the magnetic field is about $7 \mathrm{meV}$ at $T=2 \mathrm{~K}$. In the same time, the tunnel splitting of the symmetric and antisymmetric $1 e$ electronic states that was calculated by us is $4.75 \mathrm{meV}$ at $L_{b}=1.944 \mathrm{~nm}$.

Thus, the above considerations show that for samples with CdTe $Q W \mathrm{~s}$ width 18 and $21 \mathrm{ml}$ instead of the states DX in the CdMnTe $Q W$ (Line1) and IX $1 e_{\mathrm{CdTe}}-1 h h_{\mathrm{CdMnTe}}$ states (Line2), we deal with the excitons, each of which has the heavy hole in the DMS well and the hybridized electronic state whose wave functions are localized simultaneously in both the $Q W \mathrm{~s}$ in the symmetric and antisymmetric states. Of course, the levels of hybridization for the each pair of observed doublets of PL lines are dependent on the applied magnetic field and are different for two discussed samples. Nevertheless, these levels are enough for transformation of the different magnetic field dependences of the discussed DX and IX states in the discussed samples in the doublets of the parallel curves. It should be noted that the calculations of the energies of the excitons were made by method used in $[17,18]$ which automatically take into account the hybridization effects and the Coulomb interaction of the electron and hole in
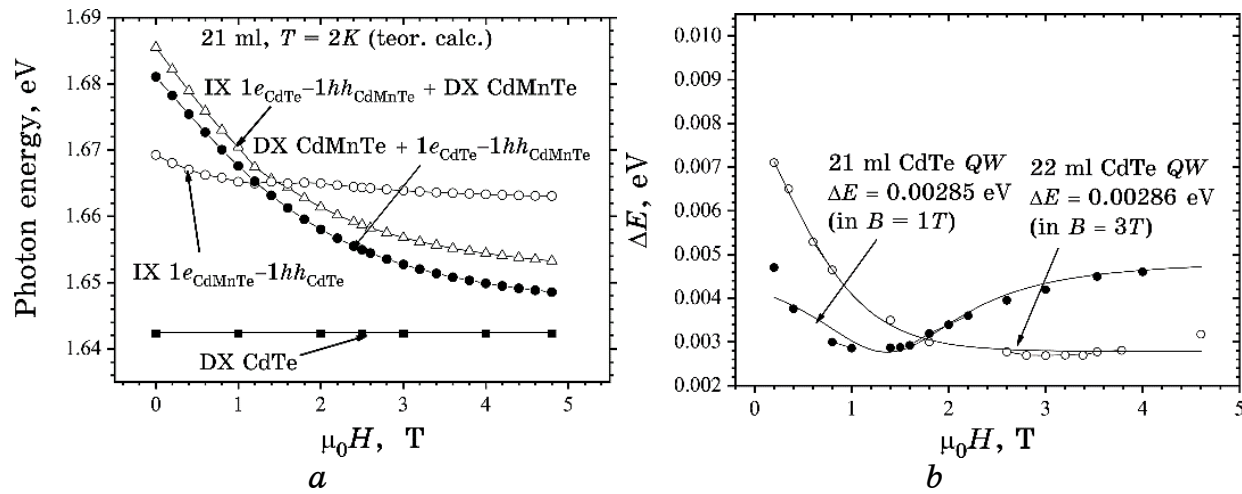

Fig. 5. a) The calculated energy positions of the DX and IX states for the structures for $L_{\mathrm{CdTe}}=21 \mathrm{ml}$ and their hybridization in certain fields; $b$ ) Splitting between two PL lines of the hybridized states (Line1 and Line2) for the 21 and 22 ml-width CdTe $Q W$ s. 
the exciton. The dependences of the binding energies on the magnetic field (and hence on the degree of hybridization) were taken into account too. One can see the results of such calculations in Fig. 5, $a, b$. From these calculations, we can draw a conclusion that the 'hybridized' DX in CdMnTe $Q W$ and IX ( $\left.1 e_{\mathrm{CdTe}}-1 h h_{\mathrm{CdMnTe}}\right)$ excitons should be observed in this system.

One can see from Fig 5, $a$, that energies levels of the IX and DX transitions unperturbed by the tunnelling at the approaching one to another of the (in different fields for the samples with different CdTe $Q W$ width), are repulsed due to the anticrossing on the energy distance of almost $3 \mathrm{meV}$. Figure $5, b$ shows the calculation of the energy difference between the components of the doublet of these lines to estimate of the mentioned repulsion for the samples with CdTe $Q W_{\mathrm{s}}$ with the widths of 21 and $22 \mathrm{ml}$. The minima of the splitting energy in certain magnetic fields correspond to the anticrossing repulsion for these structures, which indicates the hybridization of these states and on the field values of the 'precise crossing of unperturbed states'.

The goal of these calculations was not to achieve a complete numerical agreement between the calculated spectral parameters and experiment, but to get a qualitative coordination with experiment. All possible energy shifts associated with the stresses, diffuse interfaces, etc. were not taken into account. With taking into account above-mentioned one, the putted goal was reached.

The study of excitons in dual structures deserves additional experimental and theoretical attention. One of the ways of such studies can be time-resolving experiments or methods for observing photon echo (FWM) $[20,21]$ in magnetic fields and for $Q W \mathrm{~s}$ widths where the probability of hybridization causes a possibility of changing the conditions for the unperturbed resonance of the electron states by applying magnetic field.

\section{ACKNOWLEDGEMENTS}

Participation of O. V. Terletsky and S. M. Ryabchenko was partly supported by the project $7 / 19-\mathrm{H}$ of the program of the N.A.S. of Ukraine 'Basic Problems of the Creation of the New Nanomaterials and Nanotechnologies'.

\section{REFERENCES}

1. L. V. Butov and A. I. Filin, Phys. Rev. B, 58: 1980 (1998);

https://doi.org/10.1103/PhysRevB.58.1980.

2. V. B. Timofeev, A. V. Larionov, J. Zeman, G. Martinez, J. Hvam,

D. Birkedal, and K. Soerensen, Physics Uspekhi, 41: 109 (1998). 
3. A. V. Larionov, V. B. Timofeev, I. Khvam, and K. Soerensen, Sov. Phys. JETP, 90: 1093 (2000).

4. L. V. Butov, C. W. Lai, A. L. Ivanov, A. C. Gossard, and D. S. Chemla, Nature, 417: 47 (2002); https://doi.org/10.1038/417047a.

5. L. V. Butov, A. C. Gossard, and D. S. Chemla, Nature, 418: 751 (2002).

6. D. Shoke, S. Denev, Y. Liu, L. Pfeifer, and K. West, Nature, 418: 754 (2002); https://doi.org/10.1038/nature00940.

7. A. V. Gorbunov and V. B. Timofeev, JETP Lett., 83: 146 (2006); https://doi.org/10.1134/S0021364006040047.

8. P. Andreakou, A. V. Mikhailov, S. Cronenberger, D. Scalbert, A. Nalitov, A. V. Kavokin, M. Nawrocki, L. V. Butov, K. L. Campman, A. C. Gossard, and M. Vladimirova, Phys. Rev. B, 93: 115410 (2016); https://doi.org/10.1103/PhysRevB.93.115410.

9 I. I. Reshina, S. V. Ivanov, D. N. Mirlin, I. V. Sedova, and S. V. Sorokin, Phys. Rev. B, 74: 235324 (2006);

https://doi.org/10.1103/PhysRevB.74.235324.

10. A. Akimov, T. Godde, K. V. Kavokin, D. R. Yakovlev, I. I. Reshina, I. V. Sedova, S. V. Sorokin, S. V. Ivanov, Yu. G. Kusrayev, and M. Bayer, Phys. Rev. B, 95: 155303 (2017); https://doi.org/10.1103/PhysRevB.95.155303.

11. S. Lee, M. Dobrowolska, J. K. Furdyna, H. Luo, and L. R. Ram-Mohan, Phys. Rev. B, 54: 16939 (1996); https://doi.org/10.1103/PhysRevB.54.16939.

12. S. V. Zaitsev, A. S. Brichkin, P. S. Dorozhkin, and G. Bacher, Semiconductors, 42: 813 (2008); https://doi.org/10.1134/S1063782608070117.

13. S. V. Zaitsev, A. S. Brichkin, P. S. Dorozhkin, and G. Bacher, JETP Letters, 84: 340 (2006).

14. O. V. Terletskii, S. M. Ryabchenko, V. Y. Sugakov, G. V. Vertsimakha, G. Karczewski, phys. status solidi C, 14, No. 5: 1700124 (2017); https://doi.org/10.1002/pssc.201700124.

15. A. V. Komarov, S. M. Ryabchenko, I. I. Zheru, R. D. Ivanchuk, and O. V. Terletskij, Sov. Phys. - JETP, 46: 318 (1977).

16. J. K. Furdyna, J. Appl. Phys., 64: R29 (1988); https://doi.org/10.10631.341700.

17. A. V. Vertsimakha, S. B. Lev, and V. I. Sugakov, Physics of the Solid State, 46: 948 (2004); https://doi.org/10.1134/1.1744975.

18. S. B. Lev, V. I. Sugakov, and G. V. Vertsimakha, J. Phys.: Cond. Mat., 16, No. 23: 4033 (2004); https://doi.org/10.1088/0953-8984/16/23/020.

19. A. S. Davydov, Quantum Mechanics (Oxford: Pergamon Press: 1965); https://www.twirpx.com/file/2879375/.

20. J. Shah, Ultrafast Spectroscopy of Semiconductors and Semiconductor Nanostructures (Berlin-Heidelberg: Springer-Verlag: 1999); https://www.springer.com/gp/book/9783540642268.

21. A. N. Kosarev, S. V. Poltavtsev, L. E. Golub, M. M. Glazov, M. Salewski, N. V. Kozyrev, E. A. Zhukov, D. R. Yakovlev, G. Karczewski, S. Chusnutdinow, T. Wojtowicz, I. A. Akimov, and M. Bayer, Phys. Rev. B, 100: 121401 (2019); https://doi.org/10.1103/PhysRevB.100.121401. 